\title{
Onde aterrar? Como se orientar politicamente no Antropoceno
}

\author{
Down to Earth: politics in the new climatic regime
}

Dónde aterrizar: cómo orientarse en política

BRUNO EdUARDO FrEITAS HONORATO ${ }^{1}$ EVERTON RODRIGUES DA SILVA ${ }^{1}$

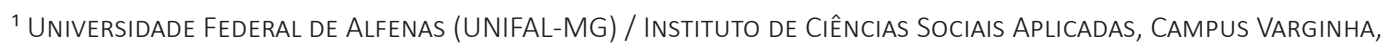
VARGINHA - MG, BRASIL

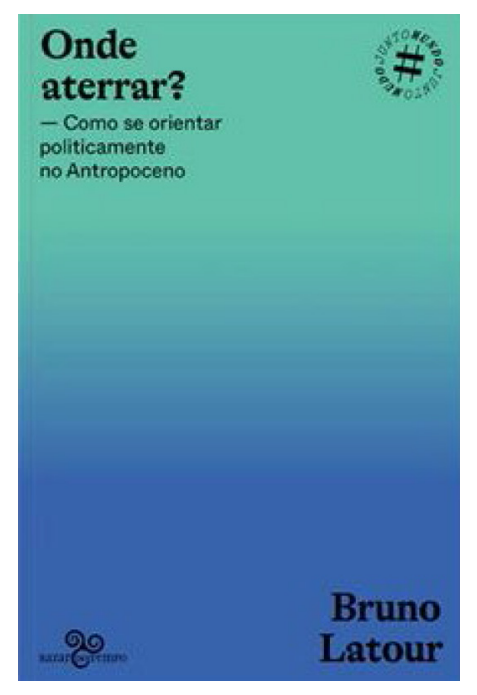

Latour, B. (2020). Onde aterrar? Como se orientar politicamente no Antropoceno (1a ed.). Rio de Janeiro, RJ: Bazar do Tempo. e-ISBN 978-65-86719-20-8.

Palavras-chave: Antropoceno. Bruno Latour. Escapismo. Negacionismo.

Keywords: Anthropocene. Bruno Latour. Escapism. Negationism.

Palabras clave: Antropoceno. Bruno Latour. Evasión. Negacionismo

Lançado em Paris em 2017 pela editora La Découverte, após a eleição de Donald Trump em 2016, e publicado no Brasil em sua versão em português em 2020, Onde aterrar? - Como se orientar politicamente no Antropoceno é o livro mais recente de Bruno Latour. Autor de trabalhos inovadores para o pensamento nas ciências humanas e sociais, como Jamais Fomos Modernos (Latour, 2013); Políticas da natureza: como fazer ciência na democracia (Latour, 2019); e Reagregando o Social (Latour, 2012), Latour (2020) oferece, em Onde aterrar? Como se orientar politicamente no Antropoceno, uma hipótese (ou ficção política, como ele mesmo denomina) para compreendermos o momento atual de crise geopolítica enfrentada em âmbito mundial. Onde aterrar? Como se orientar politicamente no Antropoceno, apesar de pouco extenso, com cerca de 150 páginas, é um livro denso, que oferece uma reflexão político-filosófica já amadurecida pelo autor.

A hipótese defendida pelo pensador francês em seu livro é a de que não compreenderemos nada sobre os posicionamentos políticos dos últimos cinquenta anos, se não reservarmos um lugar central na discussão contemporânea para o fenômeno da mudança climática do planeta - e sua negação. Segundo Latour, a desregulamentação dos Estados após a queda do muro de Berlim, a explosão das desigualdades sociais em todos os países capitalistas e a negação da existência de uma mutação climática são sintomas de uma mesma situação histórica: vivemos um momento em que as elites concluíram não existir mais espaço para elas e o restante dos habitantes do planeta.

Para o autor, quando as elites obscurantistas entenderam que, a partir da década de 1980, haveria um colapso global pela escassez de recursos, optaram por: (i) não pagar o preço que custaram à Terra, (ii) não compartilhar essa informação, (iii) construir comunidades muradas e (iv) escapar do fim se recolhendo em bunquer. A ideia de globalização foi, assim, abandonada e/ou negada - primeiro pelas elites e depois pelos seus seguidores. 
A saída de Donald Trump do acordo de Paris em 2017 e o Brexit na Inglaterra são dois marcos temporais que evidenciam essa posição de fuga do jogo da globalização. Segundo o autor, o movimento político de Trump, o "trumpismo", é o primeiro a ser pautado pela questão ecológica - embora seja fundamentado pelo seu inverso, a negação completa dessa questão. Latour defende que o "trumpismo" só foi possível nos EUA em virtude da negação das mudanças climáticas. O autor delimita essa posição política como um movimento para fora deste mundo (escapismo), uma vez que este não aponta mais para a construção de uma realidade ou um futuro comum, mas para um mundo que não existe (ou existe apenas na ilusão desse grupo).

Latour sustenta que, se antes tínhamos uma disputa pelo projeto de futuro entre os polos progressistas e reacionários ou esquerda e direita, hoje temos um abismo que leva ambos a se recolherem em suas bolhas (ou comunidades muradas) e evitarem completamente se identificar com o outro. Estamos em uma guerra de mundos não compatíveis. Dessa forma, o impasse entre as antigas posições políticas precisa ser reorientado pelos novos atratores (o Terrestre e o Fora-deste-mundo), para que possamos entender o contexto político atual e criar novas alianças entre antigos esquerdistas e reacionários. As posições e afetos políticos baseiam-se em defesas de territórios (independentemente se ideológicos ou geográficos). O Antropoceno - a descoberta de que a bioesfera é dotada de agência - instaura desafios que precisam ser enfrentados com uma nova forma de fazer política. Ficar no mundo ou escapar dele são as posições delineadas pelo autor.

Desses novos atratores políticos, o Terrestre, ou sistema terra, é aquele que, após o início do Antropoceno, passa a ser o agente principal que mobiliza os humanos a repensarem suas ações no planeta. De forma oposta, o atrator Fora-deste-mundo representa um movimento que não se direciona mais para um futuro comum, mas para uma realidade baseada em uma visão provinciana e nacionalista, de retorno a um Local (ou à era de ouro), proposta por algumas pessoas e representando um número ínfimo de interesses.

Para viver fora do mundo é preciso negar a verdade da mutação climática global e, consequentemente, negar a racionalidade cientifica. Latour explora o argumento de que as elites, ao precisar esconder a evidente finitude dos recursos, optaram deliberadamente por criar a atmosfera do negacionismo, confundindo as classes populares quanto à natureza dos fatos e financiando fake news para atrasar a conscientização dessas classes, enquanto produzem suas comunidades muradas. A negação da ciência é parte dessa estratégia. Nas palavras do autor, "Não se trata de uma política da 'pós-verdade', mas sim de uma política da pós-política, ou seja, literalmente sem objeto, na medida em que ela rejeita o mundo que reivindica habitar" (Latour, 2020, pp. 49-50).

Com isso, Latour defende que precisamos direcionar a ciência e a racionalidade para o atrator Terrestre. Todo esse tempo em que elas estiveram voltadas ao Global e ao universo afora levaram ao desprezo dos saberes ligados ao Terrestre e à perspectiva da "terra vista de dentro". A Terra "vista de Sirius" (metáfora do autor para ilustrar uma perspectiva exógena tomada pelas ciências naturais) deixa passar alguns desses pontos importantes que a ciência entende como irreais e irracionais por não terem a "objetividade" esperada. Para o filósofo, os cientistas crentes na epistemologia objetivista - defensores de que "os fatos falariam por si mesmos" -, também contribuíram para a confusão atual ao evitar a construção de um mundo comum com as classes populares. Enquanto os "racionais" se afastam e acham absurdo o novo clima de negação e atribuem o problema à falta de inteligência das classes populares, as elites obscurantistas manipulam as informações, ganhando tempo para escapar. Para Latour, a questão não se trata de um problema cognitivo das classes populares, como querem alguns dos "racionais", mas de "[...] como partilhar a mesma cultura, enfrentar os mesmos desafios e vislumbrar um panorama que possamos explorar conjuntamente" (Latour, 2020, p. 36).

Latour retoma, neste trabalho, debates de outras obras, como o questionamento da ideia de "natureza", o agenciamento dos não humanos na causalidade das relações planetárias e a ecologia política, para propor uma solução à falta de chão onde possamos aterrar nossas convicções políticas. Como proposta final do livro, o autor sugere passarmos de um sistema de produção (modo moderno e capitalista) para um sistema de geração, no sentido de gênese de um Terrestre com todos os seres humanos e não humanos que o compõem. Latour propõe que, para nos aterrarmos no Terrestre, precisamos mapear nossas dependências na condição de seres desse mundo. Isto é, por meio da descrição detalhada das nossas dependências (o que de fato nos importa, nossas posses e aquilo que nos possui), é que teremos um terreno Onde Aterrar para nos posicionarmos politicamente neste novo solo de batalhas geossociais. Trata-se do mapeamento da geografia política de cada ser (inventário dos vínculos, interesses e dependências); segundo Latour, o meio pelo qual nos situaremos em nossos coletivos (cosmos relativamente organizados de seres) e enxergaremos as possibilidades de realidades compartilháveis com os nossos pares. 
O livro é um insumo profícuo para o estudo das organizações, a começar pela possibilidade de explorar o pluralismo ontológico de Bruno Latour e sua sociologia das associações (teoria ator-rede), ancorada no exame da realidade como um resultado cambiante de agenciamentos entre humanos e não humanos, constituindo coletivos ininterruptamente. Esse caminho nos possibilita a compreensão do contexto geopolítico em que as organizações são geradas e para o qual se orientam. Latour nos faz, ainda, um convite ${ }^{1}$. Propõe que sejamos capazes de, individualmente ou em grupo, realizar um inventário daquilo a que somos apegados, de cadeias das quais estamos dispostos a nos libertar ou reconstruir e também das que decidimos interromper. É preciso ser insurgente e sonhar coletivamente novas cosmopolíticas ${ }^{2}$ do organizar.

Sem dúvida, todo sistema estabelecido apresenta uma inércia estrutural que o faz parecer inabalável. Mas não podemos deixar de reconhecer que nosso sistema atual está gerando, a cada dia, piores resultados. Vivemos uma epidemia de desilusão organizacional. Vivemos uma crise de propósito e de falta de perspectiva de engajamento coletivo, pois desconfiamos das atuais formas hegemônicas do organizar (instituições, empresas, famílias, etc.). Essa hesitação costumeira lava o solo propício para a democracia, mas também engendra uma consciência transformadora, sensível à complexidade do cosmos, semente de novos modelos organizacionais. Uma de nossas tarefas mais importantes como pesquisadores(as) do campo de conhecimento crítico dos Estudos Organizacionais (EORs) - comprometidos(as) com o florescimento de sociedades justas, inclusivas, pacíficas e ecocêntricas - talvez seja contribuir com a descolonização de nossos imaginários coletivos, participando da rebelião do futuro que já começou³.

\footnotetext{
1 "Imaginar gestos que barrem o retorno da produção pré-crise". Texto de Bruno Latour, anexo ao livro Onde aterrar? Como se orientar politicamente no Antropoceno, escrito em março de 2020 e publicado originalmente no site Analyse Opinion Critique [A.O.C] (Recuperado de https://aoc.media/).

${ }^{2}$ Isabelle Stengers sugere que produzir conhecimento - isto é, fazer ciência, produzir conhecimento sobre as organizações, etc. - é criar mundos concretos e singulares. Assim, estendendo-o à obra de Latour, esse conceito sugere que as novas políticas do organizar deverão incorporar as práticas de uma Terra que vive, como também as especificidades do agora e de cada território.

${ }^{3}$ Inspirado em uma das máximas do movimento Liberte o Futuro (Recuperado de https://liberteofuturo.net), coorganizado pela jornalista-ativista Eliane Brum: "A rebelião do futuro é no presente".
} 


\section{REFERÊNCIAS}

Latour, B. (2012). Reagregando o social. Uma introdução à Teoria do Ator-Rede. Salvador, BA: Edufba.

Latour, B. (2013). Jamais fomos modernos (2a ed.). São Paulo, SP: Editora 34.
Latour, B. (2019). Políticas da natureza: como fazer ciência na democracia. São Paulo, SP: Editora Unesp.

Latour, B. (2020). Onde aterrar? Como se orientar politicamente no Antropoceno (1a ed.). Rio de Janeiro, RJ: Bazar do Tempo.

Bruno Eduardo Freitas Honorato

ORCID: https://orcid.org/0000-0003-3670-0095

Doutor em Administração pelo Centro de Pós-Graduação e Pesquisas em Administração, Faculdade de Ciências Econômicas, Universidade Federal de Minas Gerais (UFMG); Professor Adjunto no Instituto de Ciências Sociais Aplicadas, Universidade Federal de Alfenas (UNIFAL-MG), Campus Varginha. E-mail: brunoefh@gmail.com

Everton Rodrigues da Silva ORCID: https://orcid.org/0000-0003-4708-4451

Doutor em Administração pelo Centro de Pós-Graduação e Pesquisas em Administração, Faculdade de Ciências Econômicas, Universidade Federal de Minas Gerais (UFMG); Professor Adjunto no Instituto de Ciências Sociais Aplicadas, Universidade Federal de Alfenas (UNIFAL-MG), Campus Varginha. E-mail: everton.rsilva@gmail.com 